Espacios urbanos, jóvenes habitantes de calle y covid-19

Pablo Andrés Gómez Granda, Victoria Eugenia Mena Rodríguez

Revista Argentina de Estudios de Juventud, dossier temático, e053, 2021

ISSN 1852-4907 | https://doi.org/10.24215/18524907e053

https://perio.unlp.edu.ar/ojs/index.php/revistadejuventud

FPyCS | Universidad Nacional de La Plata

La Plata | Buenos Aires | Argentina

\title{
ESPACIOS URBANOS, JÓVENES HABITANTES DE CALLE Y COVID-19
}

\author{
Urban Spaces, Homeless Youth and Covid-19
}

\author{
Pablo Andrés Gómez Granda ${ }^{12}$ \\ pabloa.gomezg@utadeo.edu.co \\ https://orcid.org/0000-0002-7233-8903
}

\author{
Victoria Eugenia Mena Rodríguez ${ }^{3}$ \\ victoria.mena@utadeo.edu.co \\ https://orcid.org/0000-0002-6163-837X
}

Facultad de Artes y Diseño

Universidad de Bogotá Jorge Tadeo Lozano

Colombia

\section{Palabras clave}

poder

ciudadanía

subsistencia

desastre

inmunidad

\section{Resumen}

Los proyectos urbanos propuestos por sucesivas administraciones de Bogotá con el propósito de resolver la problemática de los/as jóvenes habitantes de calle han sido formulados como respuestas a problemas físico-espaciales y de salud pública asociados con el consumo de drogas. La actual coyuntura de emergencia sanitaria global evidencia que estos proyectos vehiculizan tecnologías de poder que procuran el fenómeno de desespacializacion. Además de estudiar la problemática descrita, en el presente artículo se analiza una serie de elementos espaciales adecuados a la espacialización de los/as jóvenes habitantes de calle expuestos al covid-19.

\section{Abstract}

Keywords

power

citizenship

livelihood

disaster

immunity

The urban projects proposed by subsequent administrations from Bogota with the purpose of solving concerns regarding homeless youth have been developed as a response to physical and spatial issues, as well as public health difficulties associated with drug use. The crisis addressing the current global health emergency proves that these projects associate power technologies that seek despacialization trend. Besides studying the problem area previously described, the present article analyzes a series of spatial components adapted to the spatialization for homeless youth exposed to covid-19.

Recibido 19/11/2020 Aceptado 21/12/2020 Publicado 05/03/2021 


\title{
ESPACIOS URBANOS, JÓVENES HABITANTES DE CALLE Y COVID-19
}

\author{
Por Pablo Andrés Gómez Granda \\ y Victoria Eugenia Mena Rodríguez
}

\section{Introducción}

El presente artículo se interesa por la problemática de los/as jóvenes habitantes de calle en Bogotá, Colombia, particularmente, en tiempos de pandemia por covid-19. La reflexión se aborda desde tres perspectivas: espacial, política y humana, y el objetivo de la problematización es argumentar una posibilidad espacial para tales habitantes. A cada perspectiva corresponde un tema particular: a la primera, el hábitat; a la segunda, el poder; a la tercera, la ciudadanía. Los fundamentos conceptuales que sustentan el trabajo son dos vertientes del pensamiento crítico contemporáneo, las tecnologías humanas y las tecnologías espaciales, gracias a las cuales se produce tanto el análisis crítico de la situación estudiada como los argumentos propositivos.

En la primera parte del artículo se ofrece una contextualización somera sobre las características socioespaciales del área de estudio y sobre las políticas de cultura ciudadana propuestas por las administraciones recientes, con el propósito de evidenciar la falta de soluciones a la problemática de los/as jóvenes habitantes de calle. En la segunda, se analizan tres aspectos del poder en el pensamiento de Michel Foucault, a propósito de la problemática del área de estudio, de sus jóvenes habitantes desalojados/as y de su consiguiente estado de circulación constante por las calles de Bogotá. En la tercera y última parte, se desarrollan argumentos para pensar la problemática de los/as jóvenes habitantes de calle en relación con la actual emergencia sanitaria asociada al covid-19. 
Un número importante de jóvenes habitantes de calle en la Bogotá actual es consecuencia directa del célebre desalojo de la calle El Bronx, en 2016. Antes de este desalojo, Bogotá presentaba zonas con problemáticas sociales y ambientales similares. A pocas cuadras del Palacio Nacional, se encontraba el sector de El Cartucho. Conocido como Santa Inés, este sector correspondía a un prestigioso barrio del centro de la ciudad que poco a poco fue abandonado por la élite bogotana que se desplazó hacia zonas más productivas y con condiciones urbanas más favorables para la vida moderna en la ciudad.

De este modo, luego de los años sesenta, lo que otrora fuera un sector residencial privilegiado se fue transformando, paulatinamente, hasta alcanzar su máximo deterioro en la década de los noventa. Las administraciones de turno se enfrentaban a una fuerte problemática de deterioro social y espacial: las drogas, la prostitución y los grupos delincuenciales armados azotaban la zona, ubicada a escasos metros del centro histórico de la ciudad.

Desde 1991, gracias a la reforma constitucional, el país implementó una política de desarrollo territorial a través de la Ley Nacional 388/97. Desde ese momento, las ciudades debieron proponer los Planes de Ordenamiento Territorial (POT) y determinar sus objetivos de desarrollo urbano en un plazo mínimo de 15 años. En este contexto, Bogotá, en paralelo con los lineamientos políticos y de desarrollo de las administraciones de turno, debía responder a una dinámica de crecimiento y de transformación articulada que garantizara una mejor ciudad para todos, un todos que incluye, por supuesto, a los/as habitantes de calle quienes, ahora visibles por su condición de desamparo, mostraban al país los estragos de una sociedad atravesada por el narcotráfico.

En este escenario, la desaparición del barrio Santa Inés comenzó con la demolición de las construcciones, lo que obligó al desalojo de, al menos, 12.000 habitantes del barrio, entre los que se incluían administradores de los inmuebles, inquilinatos, arrendatarios, paga diario y unos 3.000 habitantes de calle.

El proyecto de renovación urbana para el deteriorado barrio Santa Inés derivó en la construcción del Parque Tercer Milenio [Imagen 1], que desplazó a buena parte de la población de habitantes de calle pocos metros hacia el norte, hacia la llamada 
calle del Bronx, en la misma localidad. Según la encuesta del censo 2017, los mayores porcentajes de cantidad de habitantes de calle por localidad se concentran en Los Mártires y en Santa Fe, con un total de 3.063, lo que equivale a 32,1\% del total de habitantes de calle en toda la ciudad.

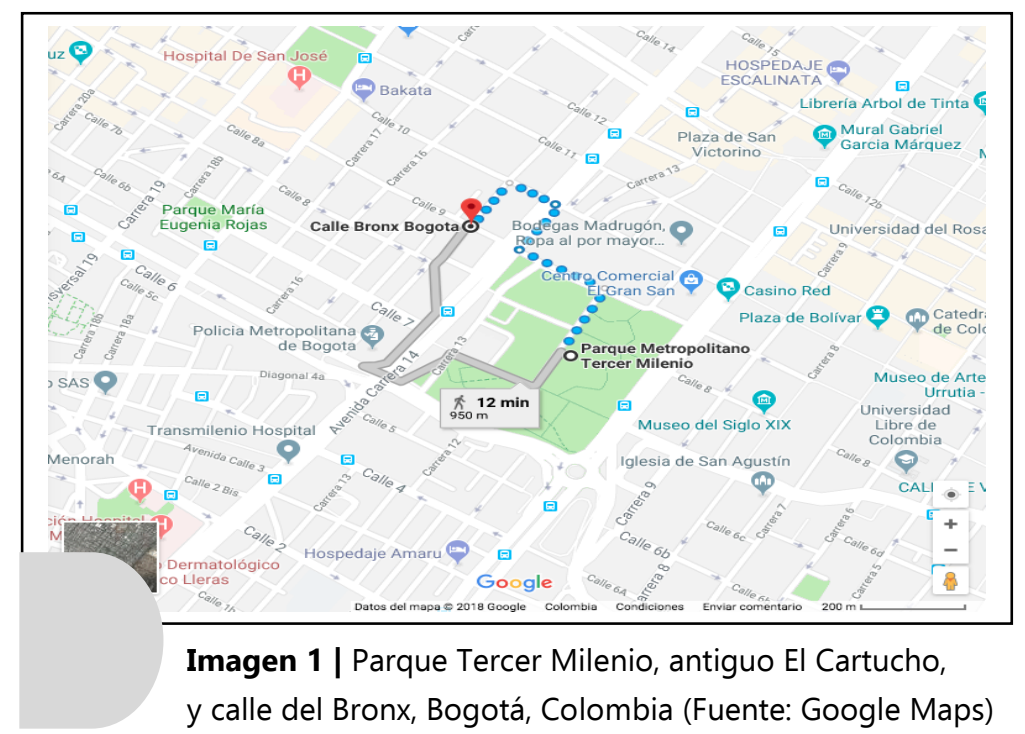

La intervención que pretendía acabar con el consumo de drogas por parte de los/as habitantes de calle y de clientes foráneos de diferentes niveles sociales produjo su traslado a otros sitios de la ciudad. Es importante resaltar que la gran mayoría de personas en condición de calle son jóvenes [Imagen 2]. Según el Departamento Administrativo Nacional de Estadística (2020), del total de población censada en 2018, 47,7\% se encuentra entre los 25 y los 39 años, mientras que los menores de 14 años y los mayores de 74 años representan menos de 1,0\%.

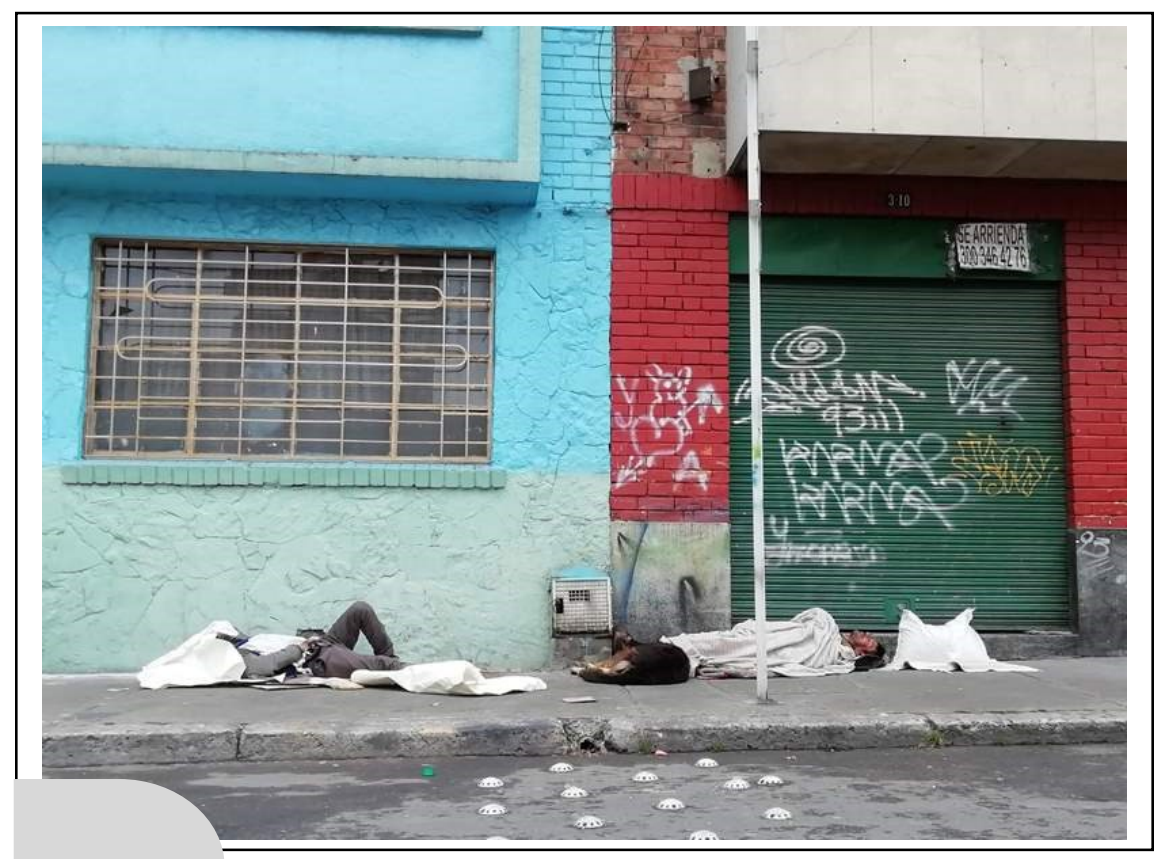

Imagen 2 | Jóvenes habitantes de calle en El Bronx (Fuente: archivo personal de los autores) 
De manera previa a ser intervenido por más de 2.500 hombres de la policía nacional y el Ejército, el 28 de mayo de 2016, El Bronx tenía el mismo destino que su antecesor a inicios de la segunda década del presente siglo y dejó un territorio devastado en términos sociales, culturales, políticos y económicos. Los/as habitantes de calle que por distintas razones no se acogieron a los programas de rehabilitación y de resocialización ofrecidos por el Distrito, nuevamente migraron a sectores vecinos, en condiciones cada vez peores.

La problemática de los/as jóvenes habitantes de calle solo se ha desplazado una vez más. Las respuestas de los gobiernos locales frente a qué se debe hacer con estos/as ciudadanos/as han oscilado entre privilegiar la reactivación del espacio físico y económico del lugar desalojado, y hacer énfasis en la solución de lo que han definido como un problema social de salud pública, dadas las dificultades que ha tenido la administración para sacar a estos/as jóvenes de la adicción a las sustancias psicoactivas. En ambos casos, la pregunta por la condición de ciudadanos/as de estas personas ha quedado en entredicho, razón por la cual, actualmente, se enfrentan a varias dificultades para acceder a las ayudas que el gobierno local ha implementado frente a la emergencia sanitaria por covid-19: sus problemas de acceso a la ciudadanía conllevan el despojo de la inmunidad espacial y biológica, el despojo de su bíos.

La inmunidad espacial y biológica es una noción construida para el presente artículo, a partir de los conceptos de bíos y zoé, de Giorgio Agamben (2002), y de la noción de inmunidad, elaborada por Paul Preciado (2020) a propósito del covid-19. En una tribuna para el diario El País de España, publicada el 28 de marzo de 2020, bajo el título "Aprendiendo del virus», Preciado argumenta cómo en tiempos de pandemia la gestión política de la vida y de la muerte sobre territorios nacionales pasa a aplicarse en los cuerpos individuales. El virus posibilita la extensión y la intensificación de las formas de gestión de la vida biológica o biopolítica (Foucault, 2004) a toda una población, socavándose de este modo la inmunidad biológica de todo individuo.

Ahora bien, a pesar del parecer de Preciado (2020), frente al virus no toda la población pierde su inmunidad biológica de la misma manera. Un joven habitante de calle se encuentra mucho más expuesto al contagio que un ciudadano con acceso a domicilio fijo. De hecho, el domicilio posibilita la inmunidad espacial aun 
cuando quien lo habita se contagie, ya que si la persona decide aislarse en su domicilio durante el tiempo de su contagio evita la proliferación del virus. Al contrario, el/la joven habitante de calle no posee inmunidad espacial y si se contagia presenta muchas más posibilidades de transmitir el virus.

Para completar la definición de la noción elaborada en este artículo, se acude al pensamiento de Agamben (2002), de donde resulta que la falta de inmunidad tanto espacial como biológica en los/as jóvenes habitantes de calle, además de minar su naturaleza biológica -lo que Agamben llama zoé-, también afecta su bíos. Se entiende, por este, la dimensión cultural y espiritual de un individuo; dimensión de la existencia más no de la supervivencia que se cultiva habitando el espacio. La situación de calle de algunos/as jóvenes, difícilmente, puede considerarse un espacio para cultivar la existencia sino que implica la supervivencia, la cual, a diferencia de la existencia, es de índole biológica. Los/as jóvenes habitantes de calle, sin espacio, sin inmunidad espacial, más que existir, sobreviven y, con el virus, su capacidad de sobrevivencia o de inmunidad biológica tiende, además, a ser anulada.

\section{Gestión del espacio: circulación de causas y efectos}

En Space, Knowledge and Power ([1982], 2001), Foucault afirma que se interesa por el espacio arquitectónico o construido en tanto «inscripto» en un campo de fuerzas; esto es, el espacio arquitectónico en situación relacional. Este espacio es más cercano a nociones como la de territorio y, sobre todo, la de medio (milieu), que resultan por demás aptas para la implementación en la población de la razón gubernamental. En el ejemplo de la ciudad del siglo XIX que Foucault propone en Il faut defender la société (1976), y que retoma al inicio de Sécurité, territoire, population (1977-1978), se define la articulación entre los mecanismos disciplinares y los dispositivos reguladores, los cuales son adecuados para la gestión de las poblaciones, sin que esto impida el funcionamiento de los mecanismos de disciplina sobre los cuerpos. De esta manera, al corte o fragmentación y a la visibilización de individuos que produce la disciplina (desde el dominio de la soberanía), se suman los dispositivos de control reguladores de conductas de la población (desde el dominio de la seguridad). 
Sobre la ciudad disciplinada y la ciudad controlada, Foucault (2004) señala:

\begin{abstract}
Digamos, para resumir todo esto, que mientras la soberanía capitaliza un territorio, instaurando el problema mayor de la sede del gobierno, mientras la disciplina arquitectura un espacio y asume como problema esencial una distribución jerárquica y funcional de elementos, la seguridad procura organizar un medio en función de acontecimientos o de series de elementos posibles, series que van a ser reguladas bajo un marco multifuncional y transformable (p. 22, traducción del autor del artículo). ${ }^{1}$
\end{abstract}

La concepción de ciudad que presenta Foucault (2004) implica potencialidades que conciernen a la ciudad contemporánea y, específicamente, a Bogotá, en tanto ciudad perteneciente a un país en vías de desarrollo, una ciudad en donde son contemporáneos y conviven la disciplina y el control, o el poder vertical y el horizontal. A continuación, se articulan algunos atributos de los conceptos de disciplina y de control con tres categorías espaciales del caso de estudio: el espacio del desastre, el espacio urbano público y el espacio de la inversión de sentido o la reorganización. Estas categorías inciden sobre la ciudad, sobre la distribución y la gestión del espacio donde sucede la relación dinámica y de exclusión entre la ciudadanía y los/as jóvenes habitantes de calle en tiempos de covid-19.

A lo largo de su historia, sobre todo de la más reciente, Colombia ha padecido desastres naturales de manera constante: temblores, desbordamientos de ríos, inundaciones de ciudades enteras, erupciones de volcanes, entre otros. El país sufre, además, las consecuencias de acciones humanas como la fumigación de cultivos ilícitos, la deforestación, el monocultivo y la explotación de la tierra por parte de compañías extractoras de energías no renovables. Estos desastres, llamados naturales, presentan relaciones con uno de los principios de la noción de seguridad en Foucault (2004), esto es, «el fenómeno de circulación de causas y efectos que es perseguido a través del medio» (p. 23, traducción del autor del artículo). ${ }^{2}$

En la línea de Isaac Newton, Jean-Baptiste Lamarck y Georges Canguilhem, Foucault (2004) piensa el medio como soporte de la circulación de una acción; circulación que obedece a una causa pero que produce también efectos sobre las masas. En este sentido, el medio hace posible un «bloqueo circular de causas y efectos» (p. 23, traducción del autor del artículo). ${ }^{3}$ A propósito, Foucault (2004) 
ilustra el ejemplo del acumulamiento: un acumulamiento grande (la causa), implica un mayor número de emanaciones malolientes y un aumento en las enfermedades (el efecto); a la inversa, una mayor cantidad de enfermedades (la causa) implica un mayor número de muertos, es decir, más cadáveres, lo que supone un aumento de acumulación (el efecto). Este ejemplo puede instruirnos sobre los desastres naturales en Colombia y sobre los desplazamientos de los/as jóvenes habitantes de la calle en tiempos de covid-19.

Un aumento de viviendas improvisadas en una zona donde las condiciones del suelo no son aptas para urbanizar (por ejemplo, las zonas sobre los bordes de los ríos) implica un mayor riesgo de desastre, una mayor cantidad de muertos posibles y, en consecuencia, un aumento en el riesgo de enfermedades en los sobrevivientes. De esto resulta una superpoblación en los hospitales (que, por lo general, no están preparados para las urgencias) y en los cementerios. Este proceso, que coincide con los efectos de la instauración del covid-19 en un territorio, el cual conlleva a la sobrepoblación, simultáneamente, es causa de otra serie de sucesos que se inscriben en el tipo de problemas que han de ser atendidos por la institución salud.

Sin embargo, la circulación de causas y de efectos descripta produce otras circulaciones que, en una escala mayor, en Colombia persiguen objetivos de seguridad: la compensación del sistema de circulación de causas y efectos, junto con la instrumentación de una serie de individuos en tanto elementos pertinentes «para obtener algo al nivel de la población» (Foucault, 2004, p. 45, traducción del autor del artículo). ${ }^{4}$ Pero a diferencia de las teorías de las «rarezas escasas» en el dominio económico, en Colombia no se intenta anular, poco a poco, ese fenómeno; fenómeno denominado desastre y que se considera sucede poco, ya que es escaso y natural, incluso si cada año se produce en momentos estratégicos y en relación con otros asuntos del gobierno (las elecciones municipales, por ejemplo). Esta postura frente al desastre, en tanto, obedece a las capacidades de los dispositivos de gestión para naturalizar un medio artificial ligado a una población. No se van a ordenar ni a planear completamente los espacios más propensos al contagio del covid-19 porque, al contrario, de lo que se trata es de disponer de lugares para el desastre. 
En el tema que nos ocupa, este proceso es similar a lo que sucedió con el sector del Bronx, dado que una gran parte de sus habitantes vivía en otra extensión, El Cartucho, dispuesta también para el desastre, pero un desastre de otra naturaleza: humano y ciudadano. Los/as habitantes de El Cartucho fueron desalojados y la Alcaldía no propuso otro espacio para estas personas, de las cuales, las que sobrevivieron a la inclemencia de la calle, luego de algunos años se establecieron en El Bronx.

Finalmente, la disposición de lugares para el desastre integra al dominio de la población, las potencialidades económicas de las series de individuos desplazados (quienes habitaban las márgenes de los ríos) o desalojados (quienes habitaban El Bronx). La integración se lleva a cabo, para el caso de lo que sucede sobre los bordes de los ríos, a través del mercado inmobiliario; para lo que acontece en lugares como El Bronx, por medio de estrategias de renovación urbana. Sin embargo, las series de individuos desplazados o desalojados difícilmente pueden pasar a integrar la población. Las potencialidades económicas del mercado inmobiliario y de las operaciones de renovación urbana también permiten, paradójicamente, la compensación del sistema de circulación causa-efecto gracias a la sustitución de las formas del hábitat de los espacios del desastre o del contagio por covid-19.

\section{Gestión de El Cartucho y El Bronx}

En general, los desastres naturales en Colombia suceden en zonas que rodean a las ciudades, caso que no es el de El Bronx que se encontraba en el centro de Bogotá. Sin embargo, el lugar donde se emplazaba este barrio se asemeja, en cierta medida, a las zonas periféricas donde suceden los desastres naturales, en tanto es un área que no responde a un trabajo de planeación reciente que represente interés por parte de la administración, pese a que permite el acceso a varios servicios urbanos como el agua y la energía.

En el caso de las periferias de las ciudades, sus habitantes son generalmente campesinos o indígenas que, en algún momento de sus vidas e historias, se vieron obligados a dejar los campos o sus tierras sagradas y llegar a la ciudad desplazados por la violencia. La migración hacia los cascos urbanos también obedece al desarrollo y a las oportunidades y las posibilidades económicas que ofrecen las grandes ciudades como Bogotá. Ahora bien, estas mismas personas, que se 
encuentran de pronto ubicadas al borde de los ríos, son las primeros en padecer los desbordamientos. De alguna manera, son utilizadas como amortiguadores y como filtro del desastre para el resto de la ciudad. Su ubicación no es dada por el azar, como se señaló, sino que obedece, por un lado, a la necesidad de estar lo más próximo posible a los servicios dispuestos al interior de la ciudad, y, por el otro, a una política de «dejar hacer» (laisser faire) por parte de la administración.

Algo similar sucede con el espacio que finalmente acogió a muchos de los/as habitantes de El Cartucho, esto es, El Bronx [Imagen 3]. Su desalojo resultó útil en tanto filtro, ya no de un desastre natural sino de operaciones urbanas que sirven como experimentación para futuros planes de desarrollo en otros sectores de la ciudad. En El Cartucho, el ejercicio urbano consistió en una renovación a la manera de tabula rasa; en El Bronx se reprodujeron los mismos términos de la operación: destruir todo lo existente y construir edificaciones que integren usos múltiples, para recuperar el sector y para revitalizar el área a fin de que se transforme en un espacio adecuado para la apropiación por parte de los denominados ciudadanos.

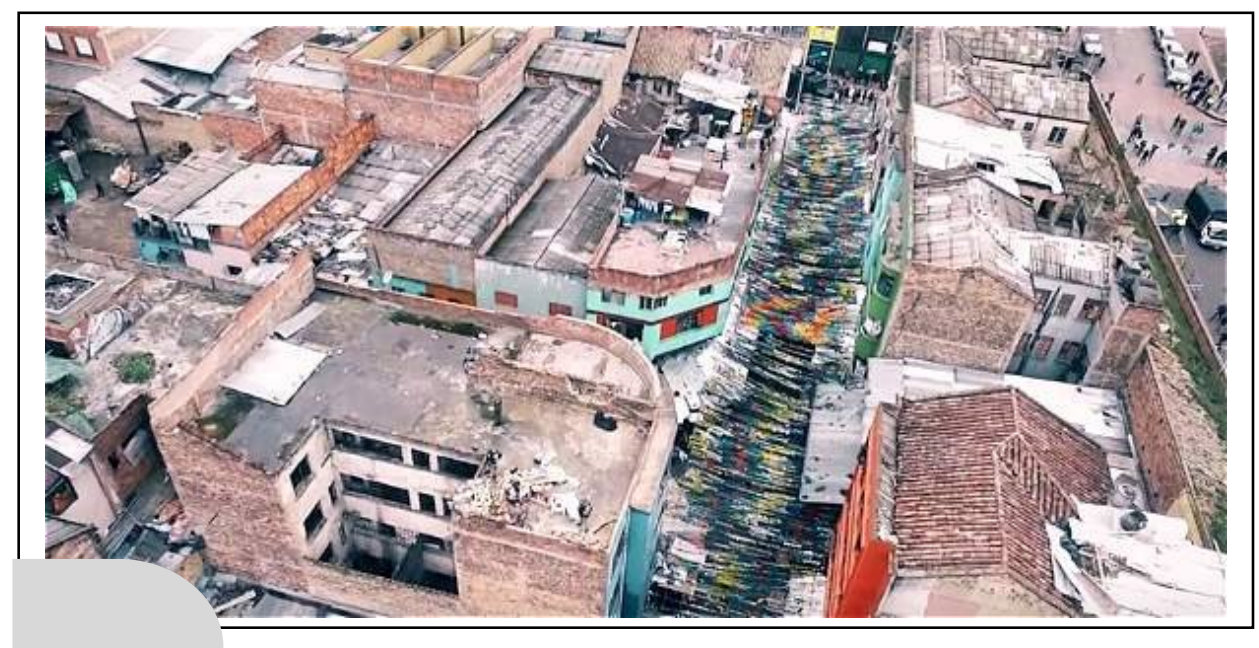

Imagen 3 | Calle de El Bronx, Bogotá, Colombia, 2015

(Fuente: periódico El Tiempo)

En términos generales, en el Plan de Ordenamiento Territorial (POT) se exponen los objetivos y las normas que después de la última década del siglo XX gestionan el espacio en Colombia. En esos planes, se entiende que los alrededores de lugares urbanizados pueden ser considerados zonas de expansión urbana. En el caso de El Bronx y El Cartucho, ubicados en el centro de la ciudad, la operación de renovación urbana implica, de facto, el hecho de considerarlos zonas de expansión urbana, como si en ellas no existiera nada o muy poco en términos urbanos físicos 
y humanos. De hecho, desde antes de las operaciones urbanas, la aproximación a los problemas que se desarrollan en estos lugares va acompañada de la concepción de proyectos cuyo objetivo es la expansión urbana de la ciudad. Una expansión al interior de la ciudad, como si existiera un no man's land que merece ser urbanizado. Si consideramos el término urbano en sentido etimológico, los dos casos expuestos (la expansión y la renovación urbana) pretenden, además de operaciones físicas (la arquitectura), que estos espacios sean adecuados para los ciudadanos, es decir, para los/as habitantes de una urbe, porque las personas que se encontraban allí originalmente no son consideradas en tanto ciudadanos/as, se les despoja de su inmunidad.

Las operaciones de expansión urbana son una manera de gestionar el futuro. Ahora bien, como se indicó, en el presente muchas de esas zonas son ocupadas por poblaciones desplazadas y, paradójicamente, tal ocupación es la base de la futura expansión urbana. Si se adiciona a esta problemática la actual emergencia sanitaria, en términos de gestión, incluso si la ocupación presente del espacio no estaba proyectada en los POT ella hace parte de esas «series abiertas [...] que no pueden ser controladas sino a través de una estimación de probabilidades» (Foucault, 2004, p. 22, traducción del autor del artículo). ${ }^{5}$ Según Foucault (2004), este modo de gestión del futuro es esencial para la aplicación de los mecanismos de control. Por lo tanto, en relación con el presente de un espacio cualquiera, cabe la pregunta: ¿cuál es el rol que juegan tanto el desastre como el desalojo y el contagio en términos de gestión?

\section{Desastre, desalojo y contagio}

Tanto el desastre como el desalojo y el contagio hacen posible la compensación del sistema de circulación causa-efecto y la instrumentalización de una serie de individuos. En efecto, desastre, desalojo y contagio son operadores del territorio, que fragmentan el estado actual de estas rarezas escasas, de estas series de individuos que no hacen parte integrante de la población, con el objetivo de extender esta misma población hacia ese territorio. Además, a través de la evacuación de víctimas y del desalojo, la serie de individuos anomalos ${ }^{6}$ se excluye del territorio que será urbanizado y, por tanto, apto para ser habitado por la población ciudadana, mas no por los/as jóvenes habitantes de calle. 
Antes del desastre, del desalojo, ni el territorio ni el área al interior de la ciudad se encontraban en completo deterioro; además, sus habitantes se lo habían apropiado a su manera. No obstante, desde la perspectiva de la seguridad y el control, tanto el territorio sobre los bordes de los ríos como El Bronx o El Cartucho se encontraban dispuestos, organizados, para el desastre y para el desalojo, esto, por la falta de planeación del uso no regulado de aquellos que lo habitaban y, sobre todo, por la falta de un trabajo de espacio, de forma. La naturaleza de tales territorios y extensiones estaba dispuesta, era propensa, para el desastre porque, en algún u otro momento, hubieran sido considerados adecuados para el desarrollo urbano.

Por lo general, y de manera muy vaga, en los POT tales áreas son consideradas de entrada, áreas de extensión urbana. En tanto, la serie de individuos, la rareza, lo escaso, la patología, no son anulados ni en el caso del desastre ni en el caso del desalojo, mucho menos en el del contagio. Al contrario, la serie es fragmentada, pero permanece como una rareza que, de hecho, al resultar fragmentada refuerza su estatus de ser, más aún, escasa y, por lo tanto, pasible de ser con mayor razón anulada. De esta manera, la serie no pierde su valor de instrumento para obtener algo a nivel de la población. Las series se ubican de nuevo en otro espacio no urbanizado (de El Cartucho a El Bronx) pero próximo a los servicios de la ciudad (el efecto) para preparar este espacio (la causa) para una nueva gestión de la población.

Desde la perspectiva de la seguridad y del control, tanto en el caso del desastre producido por lluvias o por el desbordamiento de ríos como en el provocado por el desalojo, y en la actualidad por el contagio, podría pensarse que el desastre es la etapa final de la gestión de un espacio para urbanizar. El desastre siempre existe en esos espacios donde la pobreza de las personas los lleva hacia la muerte o hacia la necesidad de exponerse al contagio para subsistir. Pero, como se señaló, tanto el desastre natural como aquel que implica el desalojo y el contagio conllevan una gestión de la población. Por lo tanto, la intervención sobre el espacio no se produce según la magnitud del desastre (cantidad de muertos, de casas desalojadas, de contagios) sino en función de su importancia: un desbordamiento de agua que afecta una zona clave de la población, inundaciones que amenazan la economía general de la población, el desalojo de lugares donde la población se degenera, la exposición al contagio de jóvenes cuya condición económica los obliga a irrespetar las cuarentenas, la exposición al contagio de jóvenes habitantes de calle. 
Esto es producto de modalidades de una economía de las rarezas escasas (Foucault, 2004, p. 43). ${ }^{7}$

Según los términos de Foucault (2004), la hambruna en Inglaterra en el siglo XVIII fue disociada para no afectar a la sociedad general, con la condición de que hubiese ese tipo de eventos para toda una serie de personas. Al referirse a la hambruna en tanto desastre, Foucault (2004) afirma que «la hambruna-plaga desaparece, pero la rareza que produce la muerte a los individuos, ella no solamente no desaparece, sino que no debe desaparecer» (p. 43, traducción del autor del artículo). ${ }^{8}$

Todas esas dinámicas de gestión también disponen, organizan, espacios públicos para mantener la relación de tensión en la población, en donde la serie de individuos es instrumentalizada a su servicio tanto como la circulación de causas y de efectos y la disposición de lugares para ser gestionados. Esta relación de tensión entre los integrantes de una población no es sinónimo de la producción de discusión que implica la noción de ciudadanía a elaborar en este artículo. Por tensión no se debe entender un sinónimo de discusión, al contrario, los espacios que producen tensión no son los mismos que permiten la discusión ni la confrontación política entre los ciudadanos.

\section{Reorganización incesante del espacio: entre los muros o la geometría inversa}

En Colombia, la circulación de las causas y los efectos surge de un proceso de gestión paradójico. En este sentido, la «maximización o la intensificación de procesos» (Foucault, 2004, p. 43, traducción del autor del artículo) ${ }^{9}$ es también un tema que concierne a los/as jóvenes habitantes de calle y a su exposición al desastre, al desalojo y al contagio. En el caso específico de El Bronx, ¿qué significa maximizar un proceso?

Generalmente, se piensa que la maximización de procesos en Europa significa el cumplimiento de los pilares del primer mundo, como la industria, y cumplimiento no es etimológicamente lejano de finalización o de perfeccionamiento. Por lo tanto, hoy en día se habla en Europa de una sociedad postindustria. Incluso, en Europa una maximización o una intensificación de procesos no implican necesariamente el perfeccionamiento de la industria. En el caso de Colombia y de su región metropolitana, Bogotá, la intensificación de procesos podría ser la condición sine 
qua non para la libre circulación de causas y de efectos. Para ilustrar este argumento, es demostrativo el espacio de combate donde se expresa la indiferenciación de dominios, que también puede observarse en los espacios frecuentados por los/as jóvenes habitantes de calle.

El espacio de combate entre fuerzas armadas se encuentra en casi todo Colombia. Al retomar la historia reciente se comprueba que casi no han existido espacios libres de combate: palacios de gobierno, iglesias, espacios públicos, el campo, la selva, el bosque, los ríos y. también, el interior de las casas. Para el combate no existen límites. Para el combate los muros son tan solo medios. La relación muros y combate evoca la obra Entre los muros (2008), de Eyal Weizman. El autor narra cómo el ataque a Naplusa, Cisjordania, en abril de 2002, revela una geometría inversa. Geometría inversa en tanto reorganización de la sintaxis urbana en medio de una serie de acciones micro tácticas. Este ataque fue realizado por fuera de las convenciones y las marcaciones espaciales de la ciudad, ya que era el movimiento de las tropas de combate lo que construía el espacio de manera incesante.

En relación con el caso de El Bronx y el desalojo de jóvenes habitantes de calle, ¿no es acaso el movimiento constante de la diáspora, el éxodo de los/as desalojados/as, lo que configura, muy a pesar de las autoridades de la ciudad, una gran parte del espacio de Bogotá? Aceptar esta posibilidad implicaría reconocer que los planes de ordenamiento territorial y las políticas públicas deberían asumir la variable «habitantes desalojados» para, así, planear la ciudad.

Entre los atributos de las tropas israelíes, aquel de atravesar los muros es bastante familiar, con todas sus implicaciones epistemológicas, ontológicas y políticas. Los primeros en atravesar los muros en Colombia fueron las guerrillas de las FARC (Fuerzas Armadas Revolucionarias de Colombia). Las relaciones entre esta guerrilla y el ejército israelí son bien conocidas; se encuentra documentado el hecho de que mercenarios israelíes instruían a la guerrilla con tácticas de guerra avanzada. En Colombia, atravesar los muros es una táctica desarrollada desde la toma de Mitú, capital del Vaupés, el 1 de noviembre de 1988 (cuatro años antes del ataque a Naplusa, en abril de 2002). Lo que sucedió en Naplusa es similar a lo sucedido en Mitú: los combates se desarrollaron «al interior de salas donde la televisión podía continuar emitiendo imágenes y la cacerola seguía en el fuego» (Weizman, 2008, p. 22, traducción del autor del artículo)..$^{10}$ 
Ya sea que el muro haya sido perforado por la guerrilla, por militares o por paramilitares, la inversión de lo privado a lo público y de lo público a lo privado es solo un atributo de una operación más general: la reorganización incesante del espacio que implica, en consecuencia, la redefinición de los bandos.

En el caso del parque Tercer Milenio que remplazó a El Cartucho, el nuevo espacio público se dirige a la ciudadanía y debería articular dos sectores de la ciudad, a partir de redefinir el espacio y sus partícipes (cosa que nunca sucedió) y de desalojar a sus antiguos ocupantes [Imagen 4]. Lo mismo se espera que suceda con el proyecto de Renovación Urbana de El Bronx, denominado Plan Parcial Voto Nacional. Lo mismo, quizás, no suceda de nuevo. La operación descrita a partir de las tácticas de guerra no implica la conquista de un territorio, sino su reorganización según los procesos que deban ser maximizados.

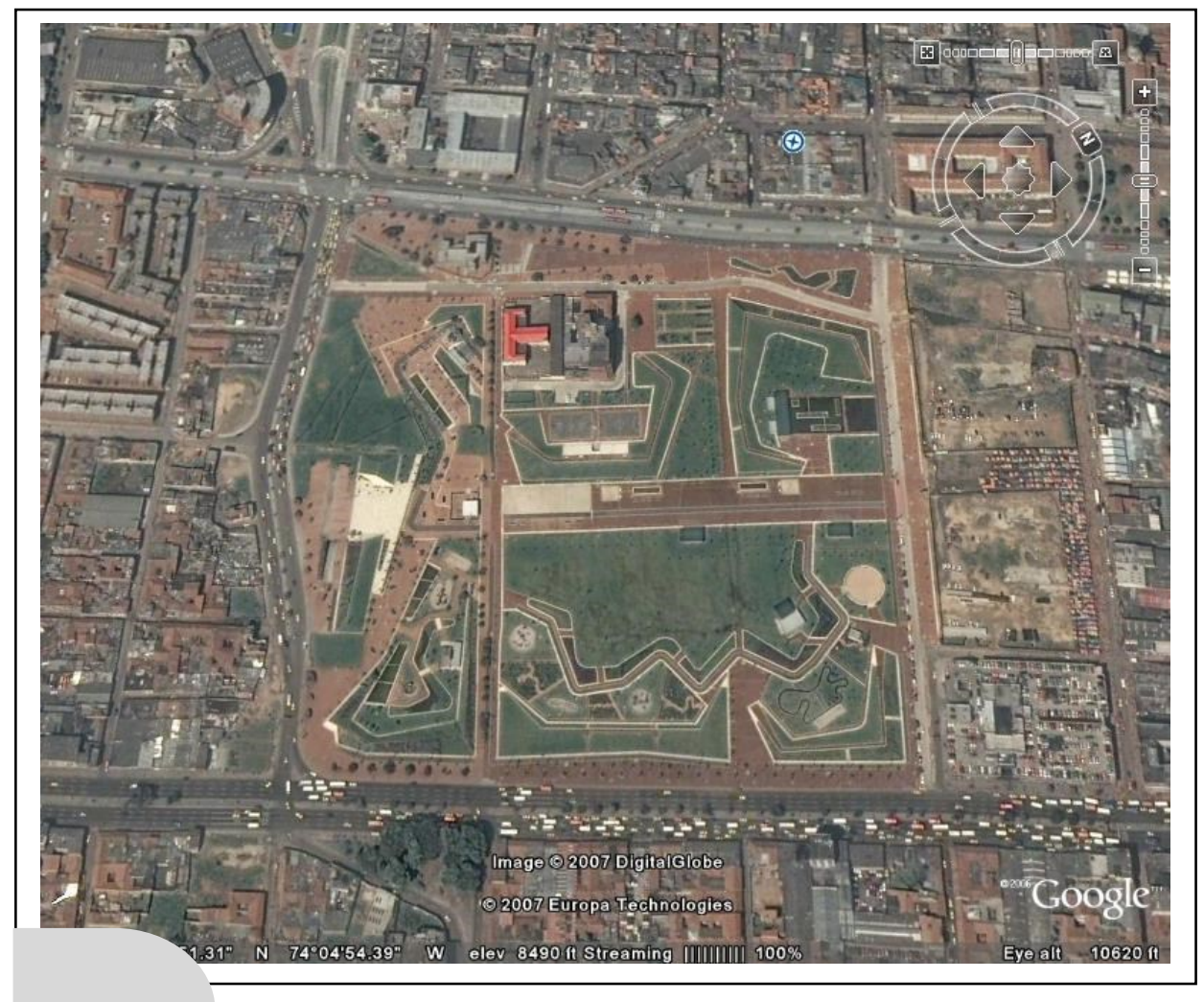

Imagen 4 | Parque Tercer Milenio, Bogotá, Colombia, 2002

(Fuente: Instituto Distrital de Recreación y Deporte, IDRD)

Los procesos de gestión en Colombia pretenden intensificar las redefiniciones incesantes de los dominios, antes claramente diferenciados, con el objetivo de mantener diferentes circulaciones y circuitos, entre ellos los del contagio, el tráfico 
(no necesariamente de estupefacientes) y cierto grado de confusión general, en la actualidad, sobretodo, con relación al covid-19.

No se conocen verdaderamente las causas y sus diferencias con sus efectos, ya que estos, como se describe desde el inicio del presente apartado, devienen causas e inversamente. Pero tampoco se conoce cuál es la fuerza contra la cual se debe combatir. Cómo definir al supuesto «enemigo» en un estado de cosas confuso, donde todo cada tanto es reorganizado y en donde lo que se produce en cada momento de reorganización es la diáspora de los/as jóvenes habitantes de calle: los de El Bronx, los de El Cartucho, aquellos que en unos años serán designados según el nombre de otro lugar, o más bien extensión, de la que hayan tenido que partir. No se trata, aquí, de designar responsables sino de analizar los procesos que encadenan todas las fuerzas en conflicto y que no permiten articular la ciudadanía a la problemática general ni a los/as jóvenes habitantes de calle.

Poco a poco, los muros de la disciplina que distribuían espacios se han vuelto irreconocibles. Una ley o una política pública también sería un muro que definiría fronteras, tal como argumenta Giorgio Agamben (1997). Debido a esto, la ley se enlaza con las distribuciones espaciales o con los «medios tecnológicos», en palabras de Foucault (2004). En Colombia, la definición de esos ambientes artificiales naturalizados no es secundaria en relación con la ley o con la norma. En algunos momentos, la ley y sus normas se transforman según lo que sucede en un territorio, por ejemplo, los desplazamientos forzados del campo a la ciudad implican la creación de nuevas normas del territorio. Los procesos de desalojo también conllevan el diseño de políticas públicas en donde la perspectiva es la de la salud pública. El término anomal implica problemas de salud pública y refiere en su origen a problemáticas del dominio de la biología, como argumenta Canguilhem ([1966] 2013).

Las nuevas reorganizaciones se encadenan a otras reorganizaciones de individuos y a dispositivos de percepción de los actores en conflicto. Lo que es primordial es la intensificación de los procesos y de las circulaciones. En este sentido, la diáspora de los/as jóvenes habitantes de calle es una intensificación de una circulación específica, en la cual estas personas, cuya integración a la sociedad es compleja, se encuentran en estado de circulación constante, es decir, sin hábitat y, en la actualidad, expuestos al contagio masivo por covid-19. 
Weizman (2008) retoma a Anna Arendt para argumentar que la caída del muro, en sentido físico y conceptual (la ley), hace posible la desaparición de la cité (no de la ciudad) en tanto comunidad política que sostiene al Estado. La categoría ciudadanía refiere, precisamente, más que a la ciudad, a la cité. Para muchos, el Estado colombiano es sostenido por su excepcionalidad. En la gestión del espacio por parte de las dinámicas de poder en Colombia y de las distintas administraciones de la ciudad de Bogotá, el Estado y la Alcaldía parecen encontrarse siempre en peligro, sobretodo, en los tiempos del Covid-19. Ambos estamentos tendrán, entonces, el derecho a reforzar las reorganizaciones y las redefiniciones, a la manera de un medio que posibilita la maximización de procesos y de circulaciones y, simultáneamente, los procesos de «bloqueo» (Foucault, 2004, p. 103). ${ }^{11}$ El Estado y las administraciones de la ciudad también se reorganizan, se redefinen, desconocen reglas legales normales, en fin, enfrentan peligros excepcionales, como el virus, que se producen dadas las reorganizaciones en las que ellos mismos participan.

En relación con la diferenciación entre espacio público y espacio privado, Agamben (1997) sostiene que «la abertura de una brecha en la frontera conceptual visual y física del muro expone nuevos dominios al poder político y ofrece, así, un diagrama físico al concepto de estado de excepción» (p. 214). Puede que esta nueva abertura, donde las partes en conflicto cambian de medio y de táctica, donde todo se desplaza para emplazarse de nuevo y reorganizarse, donde un virus convierte en privado el espacio público por efecto de las cuarentenas, no sea sino el medio mejor dispuesto para la realización de fines adecuados a los verdaderos gobernantes del país.

Si es necesario conocer cuáles son los fines y los gobernantes, si ese tipo de preguntas clásicas son todavía válidas, hay que buscar afuera, no solamente en Colombia. Esta misma abertura de una brecha es la que se efectúa en los procesos de desalojo y de exposición al virus, pero tal brecha no solo afecta al espacio físico sino también a las personas desalojadas y en condición de exposición, que resultan parte integrante del diagrama de excepción; de hecho, son un dominio móvil que permite, en cada momento de su emplazamiento en áreas dispuestas para la extensión urbana (El Cartucho, El Bronx), que la excepcionalidad se ejecute en forma de desalojo y de pérdida de inmunidad. Ellos son motivo para la efectuación de la excepcionalidad. 


\section{Ciudadanía y jóvenes habitantes de calle}

La respuesta a la pregunta sobre cómo hacer accesible a la ciudadanía un lugar que migra con sus habitantes como diáspora hacia otros lugares implica la búsqueda de soluciones que están entre lo físico y lo humano, y que poco se han considerado dentro del fenómeno de desespacialización de territorios. Se describe, a continuación, una serie de elementos espaciales que haría accesible a la ciudadanía estos espacios migrantes, por el hecho de ser, antes que soporte para las tecnologías del yo, aptos para ser practicados.

A fin de dar cuenta de estos espacios y de su relación con los/as jóvenes habitantes de calle en tiempos del covid-19, se parte de una revisión de la noción de ciudadanía, entendiéndola como un vínculo entre espacio y habitantes.

El diccionario de la Real Academia Española define ciudadano/na como un «habitante libre de las ciudades antiguas» o como una «persona considerada miembro activo de un Estado, titular de derechos políticos y sometido a sus leyes». Ahora, como sujeto relacionado con la ciudad, es decir con el contexto físico, se puede estudiar y comprender al ciudadano desde diferentes ángulos, según sea la disciplina que desarrolla el conocimiento.

Desde la perspectiva de Noam Chomsky (2007), cada persona, como parte de su proceso de crecimiento y de socialización, se apropia de su universo práctico, social, cultural y educativo, lo que le permite construir la llamada «representación interna de la realidad» (en este caso, de la ciudadanía). De esta forma, en el momento en el que actúa en el mundo la persona proyecta lo que hasta entonces ha internalizado de su relación con el universo urbano y que le ha dado las herramientas que le permiten desenvolverse de forma solvente en el entorno y con los demás a partir de una visión propia y asertiva. Esto significa que cada persona observa, actúa e interpreta la realidad según las representaciones internas que de ella ha construido. Ahora bien, las formas de actuación de un individuo sobre su realidad son las competencias que se hacen visibles a través de sus desempeños, pues son aquellas las que le permiten enfrentar situaciones diversas, solucionar problemas e interactuar con los demás.

De esta consideración, resultan dos asuntos: primero, la idea de integralidad, ya que el individuo debe desempeñarse personalmente con sus conocimientos, destrezas, actitudes, sentimientos y valores; segundo, la idea de comunicación 
verbal o no verbal, como herramienta clave para establecer acuerdos que faciliten la interacción con los demás. Puede decirse, entonces, que un individuo es más competente en la medida en que se estimule la construcción y el desarrollo de sus representaciones internas en las dimensiones intelectual, práctica y actitudinal, lo que favorece una mejor actuación sobre su vida y la modelación de una vida en contexto con los otros.

La tensión que se generó en El Bronx a la luz de estos lineamientos son más que evidentes: los/as ciudadanos/as que habitaban en la calle fueron despojados de la ciudadanía por cuenta de la ruptura entre las redes simbólicas, sociales, culturales, estéticas, económicas y políticas que convergían en el lugar y que le daban contenido a las relaciones que se tejían en el ámbito físico. Será imposible la construcción ciudadana para estos habitantes de calle, si como idea principal para disipar las tensiones se niega la relación directa que tiene el individuo en su condición humana con el espacio.

A propósito de esta relación -joven habitante desalojado de El Bronx-, se ofrecen, a continuación, algunos argumentos que, además de dar cuenta de la complejidad de tal relación, comentan elementos o principios de diseño que brindan ideas sobre cómo abordar la relación señalada en términos espaciales. Esto, por fuera de la aptitud asistencialista y de tabula rasa o de renovación urbana gestionada por las últimas administraciones de Bogotá, ya que ambas posturas ejecutan estrategias de poder, a través de espacios imperativos que impiden la consideración de lo que en adelante llamaremos «espacios practicables para la habitanía».

\section{Espacios imperativos, subsistencia y contagio}

Los espacios imperativos niegan la relación espacio-condición humana del individuo. Esta relación se produce siempre y cuando el espacio permita posibilidades de uso y, por ende, no indique un solo sentido. Entre los términos «imperativo» y «orden» existe una relación semántica que permite comprender que, incluso en espacios de usos múltiples, es decir, en espacios que se supondría ofrecen posibilidades de uso, si estos se encuentran dispuestos para fijar y para interiorizar en las personas comportamientos normalizados y excluyentes de la diferencia, es gracias a que el imperativo que los sostiene exige como contrapartida 
de la supuesta multiplicidad la desespacialización de los otros: los/as jóvenes habitantes de calle. La renovación urbana que sucedió al desalojo de los/as habitantes de El Bronx niega la relación directa que esta serie de individuos tiene en su condición humana con el espacio y, por lo tanto, bloquea las posibilidades del espacio, entre las que se cuenta la de proporcionar un hábitat a personas que subsisten de desalojo en desalojo.

Es importante observar que un «espacio imperativo» (Huyghe, 2009, p. 17) define una relación estrecha con actividades que se relacionan más con la subsistencia que con la existencia. En este sentido, para comprender tal tipo de espacios es pertinente retomar el problema de la diferencia entre la vida humana y la vida animal, trabajado por Martin Heidegger ([1927] 1986) y, más recientemente, por Agamben (2002). La vida animal -vida que el hombre también comparte por ser un «animal racional, tal como se lo identificaba en la antigua Grecia- es sinónimo de supervivencia, muy a pesar de toda la complejidad que esa vida biológica implica. De seguro, esa vida posea problemáticas biológicas bastante complejas, precisamente, porque su asunto esencial es la supervivencia. En este sentido, habría que pensar en todo lo que el desarrollo del Homo sapiens sapiens le debe a la supervivencia. No obstante, la condición humana está más allá de la supervivencia, por más compleja que esta sea. La condición humana es la existencia. A este propósito, se ha desarrollado una línea de pensamiento en la que, más allá de todas las diferencias que implican sus obras, se encuentran pensadores tan disimiles como Aristóteles, Arendt, Heidegger, Agamben y Pierre-Damien Huyghe, entre otros.

La palabra existencia viene del latín exsistentia, compuesta por un prefijo, un verbo y dos sufijos. El prefijo «ex» significa 'hacia afuera'; el verbo «sistere» denota 'tomar posición o estar fijo, fijarse o ser fijado'; el sufijo «nt» engloba al 'agente'; y el sufijo «ia» indica 'cualidad'. Existencia es, entonces, la cualidad de lo que toma posición hacia afuera, esto es, la cualidad de salir de un estado, del estado de la supervivencia. De este modo, por existencia se entiende la posibilidad de salir del estado de supervivencia y de tomar posición al respecto.

Ahora bien, para que tal movimiento se produzca hacen falta espacios que, a diferencia de los imperativos que dan órdenes, cierran posibilidades y fijan -como también denota sistere- comportamientos, permitan la posibilidad de sustraerse a la subsistencia (por más compleja que esta sea). De hecho, entre la 
locución «asistencia»-como la que se encuentra en «asistencia social»- y la locución «subsistencia» existen lazos semánticos importantes: se asiste a personas que se encuentran en estado de supervivencia como las personas de tercera edad en estado terminal.

Este tipo de personas luchan, sobre todo, por su supervivencia, por su vida biológica, mas no por la existencia que prodiga la condición humana. En este sentido, el contagio del covid-19 enfatiza la dimensión de supervivencia de todo ciudadano, dimensión que en los/as jóvenes habitantes de calle se multiplica, ya que a diferencia de los ciudadanos que más vale se encontraban abrigados por la dimensión de la existencia antes de la emergencia sanitaria, y sobre todo luego de los procesos de desalojo padecidos, siempre se han encontrado expuestos, sin inmunidad biológica ni ciudadana, dentro del dominio de la subsistencia.

Los/as jóvenes habitantes de la diáspora, aquellos que salieron de El Cartucho, que llegaron al Bronx y que en la actualidad transitan de manera incesante Bogotá, aquellas series de individuos útiles en tanto filtros para los planes de expansión y de renovación de la ciudad, no existen, subsisten, y su subsistencia en tiempos del covid-19 se dobla, se intensifica. Así se instalen para ellos «espacios de tránsito» -espacios donde los/as habitantes de la calle pueden ingresar en la mañana y disfrutar de un baño, de un cambio de atuendos, de un desayuno y de una rápida atención medica-, así estos espacios se hubiesen construido en la ciudad, cosa que hasta ahora no ha sucedido, los/as jóvenes habitantes de la calle seguirían siendo habitantes de la calle.

En la misma denominación, «jóvenes habitantes de calle» la posibilidad de una existencia, de un tomar posición hacia afuera de un estado determinado, es negada. El estado determinado para estas personas es la movilidad incesante, la cual para permitir la opción de salir de ella, en tanto ámbito propio de la supervivencia, necesita de un lugar. Sin lugar establecido, la posibilidad de salir de un estado es imposibilitada. Precisamente, si se sigue la línea de pensamiento que proviene de Heidegger respecto de lo que él llama «habitar», en tanto condición esencial de la humanidad, para que tal habitar se efectúe es necesario, primero, un lugar que permita realizar el movimiento que va de la subsistencia (zoé) a la existencia (bíos) o vida política. 
En los tiempos del covid-19, todo ciudadano, tal como señala Agamben (1997), se encuentra más en la dimensión de la subsistencia que en el de la existencia, gracias al estado de excepción instaurado por los Estados con el propósito de contrarrestar la expansión del virus y de asistir la subsistencia de los infectados. Sin embargo, tal asistencia se procura a quienes, encontrándose actualmente en estado de subsistencia, provienen de un estado de existencia y de ciudadanía establecida por su pertenencia a un lugar. En el caso de los/as jóvenes habitantes de calle, su permanente estado de subsistencia no es asistido porque no cumplen con la condición de procedencia existencial y ciudadana otorgada por un lugar.

Habitar la calle implica, en la denominación misma, un contrasentido, no se puede habitar la calle porque esta difícilmente permite echar raíces, es decir, hacer lugar. A este respecto, es instructivo pensar en el denominativo con el que se llama a estas mismas personas en Francia: «sin domicilio fijo». Esto implica que las personas que se encuentran en la calle no poseen por el momento un domicilio fijo, por el momento. Sin embargo, «sin domicilio fijo» también implica que las personas de la calle poseen un domicilio que no es fijo sino móvil. En este sentido, si se intenta comprender desde otra perspectiva la denominación «habitar la calle», puede inferirse que finalmente, a pesar de estar orientada al tránsito y no a la estancia, la calle permite el habitar. No sería, entonces, un espacio imperativo; al contrario, contendría, incluso, la posibilidad de habitarla.

\section{Espacios practicables y habitanía}

Habitar la calle con la posibilidad de pasar de la supervivencia a la vida, o a lo que aquí se ha denominado existencia, ¿es algo que podría suceder en Bogotá? ¿La diáspora de El Bronx podría seguir en la calle, pero habitándola con todo el sentido que encierra esta palabra? ¿Qué cambios implica, en las políticas públicas y en su relación con el poder, en los planes de ordenamiento territorial, en las operaciones urbanas y arquitectónicas, en los procesos de asistencia inmunológica actual y de transferencias monetarias a hogares pobres, asumir que hay habitantes de la calle que en realidad habitan la calle, que se realizan en la calle en tanto lugar donde se produce su humanidad e inmunidad por fuera de todo encierro? De hecho, ¿es posible para planes de ordenamiento y de planeación asumir que la calle también se puede habitar como lugar adecuado para la humanidad y la inmunidad? 
Los elementos tanto de las políticas públicas como del diseño espacial que puedan asumir este tipo de preguntas son desconocidos y no se pueden establecer aquí. Sin embargo, en este artículo sí se argumenta a propósito de una condición de posibilidad que permitiría acompañar procesos en los que los/as habitantes de calle no sigan siendo excluidos, ni por las denominaciones de las políticas públicas ni por los proyectos de planeación, ni por los procedimientos de asistencia asociados a los tiempos del covid-19. Ya sea por la vía de la aceptación de que en realidad hay gente que habita la calle, o por la vía de la generación de lugares estables donde tales habitantes dejen la calle para habitar otros lugares más adecuados a la realización de sus singulares existencias, la noción de habitanía arroja luces.

Por habitanía se entiende la síntesis entre habitar y ciudadanía. ¿Acaso quiere decir esto, entonces, habitar la ciudadanía? ¿O más vale que la ciudadanía sea un hábitat? No necesariamente. Habitanía está más asociado a la relación entre habitar y ciudadanía en términos espaciales: arquitecturas que especialicen la habitanía, esto es, aspectos esenciales del habitar y de la ciudadanía. Del habitar, se considera esencial el hecho de que quien habita cultiva su humanidad y su inmunología. De la ciudadanía es crucial la posibilidad de que quien la ejerce pueda estar de frente ante la presencia del otro. Cultivar su humanidad y presenciar al otro. Desde esta perspectiva, habitanía implica los dominios del sí mismo y del otro. ¿Cómo lograr esto? A través de espacios practicables que permitan o que estén orientados hacia la discusión. En la discusión, en el intercambio de la palabra, se cultiva la humanidad y se atiende la presencia del otro. Pareciese la cosa más sencilla. Pero no, eso no sucede.

Ahora bien, retomando la última pregunta, si el cómo se da a través de la producción de la discusión, para que esta se produzca es necesario un espacio. En efecto, como se sobreentiende, con la habitanía se trata de actualizar en las ciudades el carácter de cité. Tal como Weizman (2008) y Agamben (1997) lo habían diagnosticado, la caída del muro conceptual y físico implica que las ciudades desplacen la cité y sus posibilidades. Sin embargo, el presente artículo afirma una re-volución del muro, esto es, un regreso del o al muro. Esta perspectiva no es melancólica. Interesa re-tomar algo del pasado que ya se ha esfumado, el muro, o que utiliza el señor Trump para desterritorializar y para desespacializar. Interesa, sí, la discusión entre iguales que se producía gracias al espacio de la polis donde 
se ejecutaba la cité (Sennet, 2019, p. 17), pero no el espacio en sí mismo. Interesan los espacios actuales de los tiempos del covid-19, los contemporáneos.

No se pretende, empero, afirmar una especie de vuelta a la arquitectura antigua, por lo que es menester describir los espacios que permitirían, no las diferenciaciones que implicaba el muro, sino la práctica de la discusión contemporánea. Un espacio para la discusión, un espacio en donde gracias a la discusión se cultive la humanidad y la inmunidad para cada una de las personas que discuten, y se confronte, se atienda la presencia del otro, es un espacio que por sí mismo da a discutir. La posibilidad de la discusión entre personas no puede efectuarse si no es a partir de la discusión. Un espacio no puede orientar o dar la posibilidad de la discusión si no es a partir de que él mismo sea discutible y, para ello, ese mismo espacio debería ser practicable.

A diferencia del espacio imperativo que da órdenes y que tiene un solo sentido, el espacio practicable ofrece posibilidades. El caso ejemplar sería el aparato mecánico de fotografía. Este se ofrece al usuario en sus múltiples posibilidades de reglaje, de ajuste, de regulación, de corrección. La postura del individuo ante un aparato de estos merece de toda su atención, ya que la imagen a producirse no surge de manera automática, necesita de la manipulación de la persona que debe ajustar la profundidad, la entrada de luz, la sensibilidad, entre otros reglajes. Esta relación de atención entre quien manipula el objeto y lo que este le ofrece (diferente a imponer), es esencial a la humanidad y a su inmunología (su potencia de ser inmune en tanto perteneciente a un lugar). De hecho, el término manipular no es el más adecuado para describir la relación aparato-individuo, porque tal término da a entender que el individuo se sirve, a sus anchas, del aparato. Tampoco sucede que el aparato se sirva, manipule al/la usuario/a. La instrumentalización entra aquí en paréntesis. Entre ambos, se genera una dinámica en la que individuo y aparato ofrecen de sí mismos al otro y en donde la imagen resultante es producto de esta relación. Esa oferta de posibilidades del aparato ante el individuo es mediada por el cuestionamiento: ¿qué profundidad escoger, qué sensibilidad es la más indicada para «captar» un objetivo?

Este tipo de espacios practicables adecuados a la habitanía no son eminentemente funcionales, al contrario, implican una caída en los términos de la funcionalidad inmediata y automática que se realiza en espacios imperativos como sucede, 
por citar un ejemplo extremo, con el torniquete que obtura la entrada de los/as usuarios/as al Transmilenio ${ }^{12}$ en Bogotá.

Como sucede ante la presencia humana, la presencia de un espacio puede generar preguntas, y ante estas, la atención del otro. Quien observa al otro despierta su atención para intentar así abordar su presencia. Hablamos, entonces, de espacios trabajados formalmente que generen atención, e impidan comportamientos automáticos producidos por espacios excesivamente funcionales o imperativos.

El trabajo de forma descrito implica, además, que la presencia de los espacios se exponga. A este propósito, el proyecto de Rem Koolhaas y su agencia OMA, para el concurso de Les Halles en París, presenta un espacio público ejecutado por encima de las líneas de metro y de trenes de cercanía -a través de un trabajo técnico que produce formas que muestran en la superficie lo que se encuentra abajo-, que expone lo que otros proyectos para el mismo concurso ocultaban o cubrían, las mismas vías de las líneas de metro. Este proyecto hace todo lo contrario de un proyecto reciente en Bogotá que, como las operaciones de renovación urbanas, hacen desaparecer el espacio sobre el que se montan, cubriéndolo. El proyecto referido es El Parque Bicentenario [Imagen 5], en donde la superficie propuesta oculta las vías existentes. ${ }^{13}$

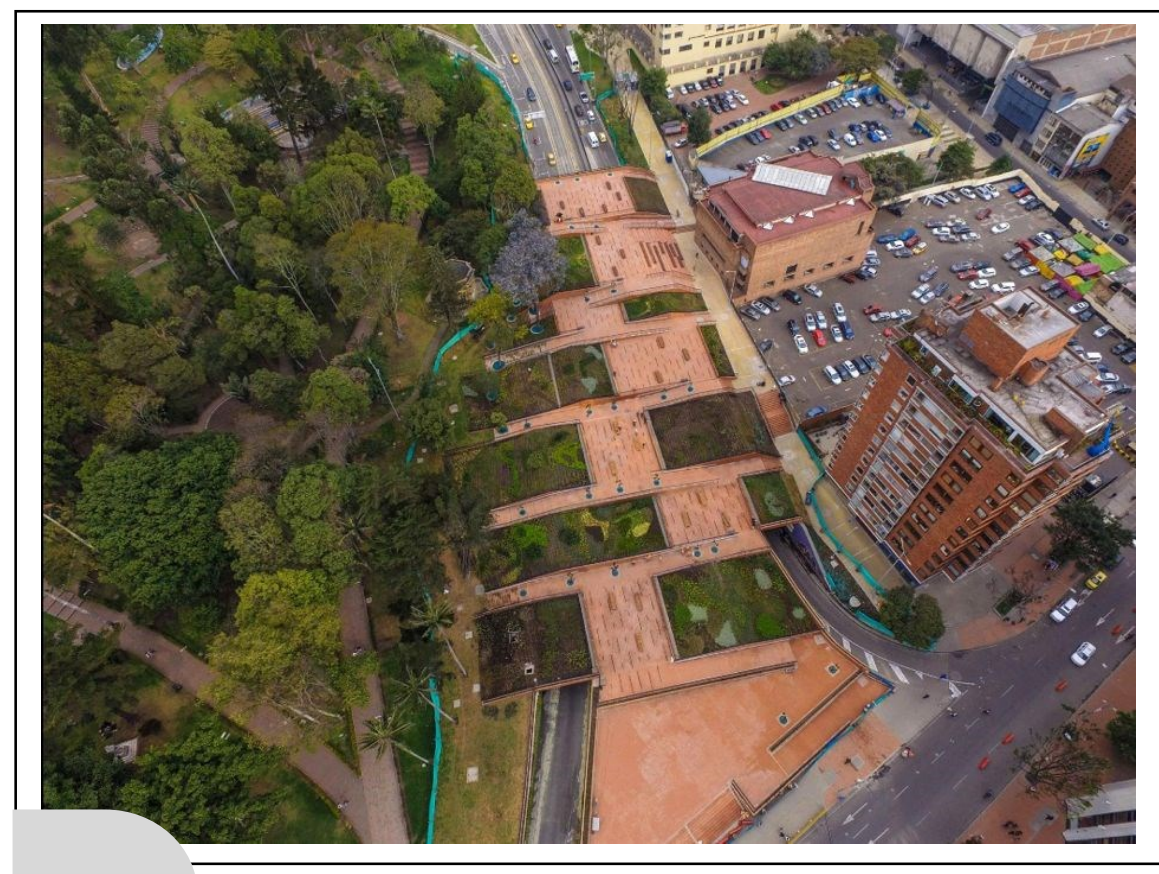

Imagen 5 | Parque Bicentenario, Bogotá, Colombia.

Firma Mazzanti Arquitectos, 2017 (Fuente: ArchDaily) 
Los espacios que no distraen, que despiertan la atención -gracias a un trabajo de forma que solicita la sensibilidad de las personas-, hacen posible que los mismos espacios sean discutibles, que den de qué hablar. Si en tales espacios la atención, al contrario de ser distraída, es ofrecida, se cultiva la humanidad, para la cual, en términos de Uexküll (2010), Heidegger, Agamben y Sennett, la atención es condición sine qua non. De hecho, en la noción de habitar se encuentra la atención como recurso. La persona se realiza en un lugar, lo habita, porque está atenta a él. Los espacios donde la humanidad no se cultiva, no permitirían, entonces, la emergencia de la atención a través de su oferta formal. Tales espacios solicitan a la persona de tantas maneras, al punto de excitarla, que la distraen e impiden que logre focalizarse, interesarse, atender la oferta formal de algo que llame su atención. Por el contrario, su atención se encuentra dispersa, fragmentada, a la manera como el poder fragmenta las series de individuos en los casos de desastre y de desalojo. El poder de dispersión y de fragmentación, esto es, de cortar las potencialidades de un ser o de grupo de personas, también ataca una capacidad humana esencial: la posibilidad de discusión.

En términos de la discusión con el otro que la noción de habitanía propende, el hecho de que los espacios descritos se expongan en su presencia y no se cubran, no se oculten, permite, en un segundo momento, el conocerlos. En la noción de ciudadanía el término reconocer es importante. En reconocer se implica el volver a conocer: re-conocer (de allí que se marque la variación semántica que lleva del re-conocer al conocer). Se puede conocer, o al menos, empezar a conocer, aquello que se presenta sin ocultarse, o aquello que si está oculto invita a ser desnudado para conocerlo. Se trata, entonces, de espacios desnudos o que presentan la posibilidad de ser desnudados pero que, en ambos casos, implican la potencia de la exposición.

Que el otro se exponga, que lo otro se preste para ser expuesto en su presencia ante un/a usuario/a, es un gesto de ciudadanía, un gesto que cultiva la ciudadanía. Ese gesto no se encuentra en los espacios públicos que cubren lo existente ni en las operaciones urbanas de tabula rasa -como el proyecto de El Bronx que desespacializó a los/as jóvenes habitantes de calle-. En ambos casos, lo otro, sean las arterias de la ciudad o el lugar anulado de los/as habitantes de El Bronx, no se presenta, no se expone para ser conocido. Por lo tanto, algo esencial a la ciudadanía se evade. Estos espacios no son practicables, precisamente, porque 
la praxis, esto es, la acción humana, esa que diferencia al hombre de otras formas de vida, no se puede efectuar: la praxis humana, la discusión; en suma, la política.

Aunque sus prácticas fueron diferentes a lo aquí bosquejado, la segunda administración del alcalde Antanas Mockus (2001-2004), pretendía, también, cultivar la ciudadanía a través de gestos. Entre las estrategias que desarrollaba para ello, resalta la de los mimos. De hecho, la figura del mimo es la esencia misma del gesto. En el gesto del mimo, la acción no se produce, la potencia nunca pasa al acto, nunca se realiza, no se agota. ${ }^{14}$ Un gesto tal no es adecuado a la explicación que lo agota o lo explica, el gesto está más bien orientado al comentario (término que contiene el latín mens, que también encontramos en memoria). Proyectar espacios como gestos, como formas que den sobre qué comentar, como formas para recordar, es proyectar espacios para la discusión, porque se discute, aun, lo que no se agota en una explicación. Así, tales espacios serían practicables porque posibilitan la praxis humana, la palabra, la discusión con los otros, incluidos los/as jóvenes habitantes de calle, con lo cual se posibilitaría, si no su pertenencia a un lugar, su posibilidad de frecuentación.

\section{Conclusión}

En Bogotá y en Colombia existe actualmente y desde hace algunos años un auge de lugares de la memoria en donde se rememora la violencia sucedida, sobretodo, en municipios donde no existía la intervención del Estado o en las periferias de las ciudades (así esas se encuentren al interior de las ciudades como en el caso del Bronx). A diferencia de estos espacios de crucial importancia para la reconciliación de la sociedad del posconflicto, los espacios adecuados para la habitanía no se sostienen exclusivamente sobre las facultades de la memoria ni sobre la redención a través del recuerdo. Estos espacios se prestan más bien a experiencias de duelo bastante íntimas, así sean frecuentados por multitudes.

Los espacios practicables para la habitanía infieren la discusión activa y publica, no rememoran, al contrario, presentan y, sobretodo, no narran historias, buscan incidir en la construcción de nuevas interpretaciones y formas de vida -no en la construcción de otras historias- donde a los/as jóvenes habitantes de calle se les conozca en espacios que les den cabida, lugar: espacios donde ellos también sean, 
al menos, una posibilidad de discusión y, quizás, el posible otro con el que se discute. Sea «objeto» o mejor, tema de discusión, sea el otro con el que se discute, en ambos casos, los espacios practicables favorecen la habitanía porque en ellos, sin ser fragmentados, mermados, ocultados ni doblemente expuestos al covid-19, todos cuentan con un lugar.

\section{Referencias}

Agamben, F. (1997). Homo sacer. Tome 1. Le pouvoir sacré et la vie nue (Trad. Marlène Raiola). París, Francia: Seuil.

Agamben, F. (2002). L'Ouvert: De l'homme et de l'animal

(Trad. Joël Gayraud). París, Francia: Payot \& Rivages.

Agamben, F. (2018). Karman. Court traité sur l'action, la faute, le geste (Trad. Joël Gayraud). París, Francia: Seuil.

Canguilhem, G. (2013) [1966]. Le normal et le pathologique.

París, Francia: PUF.

Chomsky, N. (7 de marzo de 2007). El control de los medios de comunicación [Entrada de Blog]. Recuperado de

http://www.voltairenet.org/article145977.html

Departamento Administrativo Nacional de Estadísticas (DANE). (2020). Censo Nacional 2018. Recuperado de https://www.dane.gov.co/index.php/estadisticas-por-tema/demografiay-poblacion/censo-nacional-de-poblacion-y-vivenda-2018

Foucault, M. (1997). Il faut défendre la société. Cours au Collège de France (1976). París, Francia: Gallimard, Seuil. 
Foucault, M. (2001). Space, Knowledge and Power [Espace, Savoir et Pouvoir], entretien avec P. Rabinow (Trad. F. Durand-Bogaert). En F. Ewald, D. Denfert y J. Lagrange (Eds.), Dits et Écrits II (1976-1988) [pp. 182-197]. París, Francia: Gallimard, Seuil.

Foucault, M. (2004). Sécurité, territoire, population. Cours au Collège de France (1977-1978). París, Francia: Gallimard, Seuil.

Huyghe, P-D. (2009). Modernes sans modernité. Éloge des mondes sans style. París, Francia: Lignes.

Heidegger, M. (1986) [1927]. Être et temps (Trad. François Vezin).

París, Francia: Gallimard.

Ley Nacional 338 (1997). Ley de Desarrollo Territorial.

Recuperado de https://www.funcionpublica.gov.co/eva/gestornormativo/norma.php?i $=339$

Preciado, P. (28 de marzo de 2020). Aprendiendo del virus. El País.

Recuperado de

https://elpais.com/elpais/2020/03/27/opinion/1585316952_026489.html

Sennet, R. (2019). Construir y habitar. Ética para la ciudad

(Trad. Marco Galmarini). Barcelona, España: Anagrama.

Uexküll, J. V. (2010). Milieu animal et milieu humain (Trad. C. M. Freville). París, Francia: Payot \& Rivages.

Weizman, A. (2008). À travers les murs. L'architecture de la nouvelle guerre urbaine. París, Francia: La Fabrique. 


\section{Notas}

1 Texto original: «Disons, pour résumer tout cela que, alors que la souveraineté capitalise un territoire, posant le problème majeur du siège du gouvernement, alors que la discipline architecture un espace et se pose comme problème essentiel une distribution hiérarchique et fonctionnelle des éléments, la sécurité va essayer d'aménager un milieu en fonction d'événements ou de séries d'événements ou d'éléments possibles, séries qu'il va falloir régulariser dans un cadre multivalent et transformable» (Foucault, 2004, p. 22).

2 Texto original: «Le phénomène de circulations des causes et des effets qui est visé à travers le milieu» (Foucault, 2004, p. 23).

3 Texto original: «Bouclage circulaire des causes et des effets» (Foucault, 2004, p. 23).

4 Texto original: «Obtenir quelque chose au niveau de la population» (Foucault, 2004, p. 45).

5 Texto original: «Séries ouvertes [...] qui ne peuvent être contrôlées que par une estimation de probabilités» (Foucault, 2004, p. 22).

6 «Anomal» es un término que Foucault recupera de su maestro Georges Canguilhem, con el fin de señalar su diferencia con el término anormal. A grandes rasgos, en anomal no se encuentra todavía la designación negativa y excluyente de anormal y, sobretodo, en el dominio de la biología, es una especie de mutación gracias a la cual evoluciona un organismo o un medio. Se retoma este sentido para señalar que las series de individuos descriptas en el texto son útiles en tanto permiten la evolución y la reorganización de un medio.

7 Término original: «Raretés» (Foucault, 2004, p. 43).

8 Texto original: «La disette-fléau disparaît, mais la rareté qui fait mourir les individus, elle, non seulement ne disparaít pas, mais ne doit pas disparaitre» (Foucault, 2004, p. 43).

9 Texto original: «Maximalisation ou les intensifications de processus» (Foucault, 2004, p. 43).

10 Texto original: «Dans des salons où la télé pouvait très bien continuer d'émettre et la casserole demeurer sur le feu» (Weizman, 2008, p. 22).

11 Término original: «Bloucage» (Foucault, 2004, p. 103).

12 Transmilenio es un sistema de transporte de tipo BRT (Bus Rapid Transit) que hace parte del sistema de transporte masivo de Bogotá. Su construcción se inició en 1998 y fue inaugurado el 4 de diciembre de 2000. Entró en operación el 18 del mismo mes con las troncales (líneas) de la Avenida Caracas y de Calle 80. Forma parte del Sistema Integral de Transporte Público (SITP) de Bogotá y presta servicios de transporte urbano, complementario y especial, que circulan por los barrios y las vías principales de la ciudad.

13 Proyecto ideado por la firma Mazzanti Arquitectos.

14 A propósito del gesto como praxis que no se agota, ver Agamben (2018). 